\title{
Reproductive behaviour of sneaker males of the peacock blenny
}

\author{
D. Gonçalves*, T. Fagundes and R. Olliveira \\ Unidade de Investigação em Eco-etologia, Instituto Superior de Psicologia Aplicada, \\ Rua Jardim do Tabaco 34, 1149-041, Lisboa, Portugal
}

(Received 25 July 2002, Accepted 29 May 2003)

\begin{abstract}
In the peacock blenny Salaria pavo small sneaker males tried to steal 'fertilizations' at most in two different nests of large nesting males throughout the breeding season and spent most of their time associated with a particular nest. Sneakers did not associate with ripe females. As nesting males were the limiting reproductive resource in this population due to the scarcity of appropriate nest sites, sneakers were likely to maximize their chances of achieving parasitic fertilization of eggs by associating with successful nests. - 2003 The Fisheries Society of the British Isles

Key words: alternative reproductive tactics; peacock blenny; Salaria pavo; sneaking behaviour.
\end{abstract}

Many teleosts exhibit male alternative reproductive tactics where large 'bourgeois' males compete for resources such as females or nesting sites, while small males parasitize the investment of bourgeois males (Taborsky, 1994, 1997, 2001). Sneakers are parasitic males that rely on inconspicuous approaches in order to fertilize eggs during spawning events between bourgeois males and females. Sneakers can be predicted to adopt at least two different reproductive tactics to maximize their reproductive success: (1) to follow a ripe female until it spawns with a bourgeois male and parasitize the mating event; (2) to associate with bourgeois males preferred by females and wait for spawning episodes to occur.

In this study the reproductive tactics adopted in the field by sneaker males of the peacock blenny Salaria pavo (Risso) were investigated. The population studied occurred at Culatra Island (Algarve, southern Portugal; $36^{\circ} 59^{\prime} \mathrm{N}$; $7^{\circ} 51^{\prime} \mathrm{W}$ ) in an area where there was a scarcity of appropriate nesting sites, and bourgeois males adopted nests in the holes of bricks that were used to delimit the edges of clam culture fields. Bourgeois males did not defend any territory around the nest (it was even common to find males breeding in adjacent holes of the same brick) and stayed most of the time inside the nest in order to avoid losing it to a competitor (Almada et al., 1994). Small males were unable to acquire a nest and thus reproduced as sneakers (Almada et al.,

\footnotetext{
*Author to whom correspondence should be addressed. Tel.: +35121 8811700; fax: +351 21 8860954; email: davidg@ispa.pt
} 
1994; Gonçalves et al., 1996). At the peak of the breeding season most nests were fully covered with eggs and the nest area potentially became a limiting factor for females (Almada et al., 1995; Oliveira et al., 1999). The operational sex-ratio was thus biased towards females that competed for access to the few available nests and actively courted bourgeois males (Almada et al., 1995). Sneakers imitated the females' morphology and courtship behaviour to approach nests during spawning events in order to try to fertilize eggs (Gonçalves et al., 1996) and bourgeois males attacked and courted sneakers and females with the same frequency, suggesting that sneakers were able to deceive bourgeois males (unpubl. data). The two male alternative reproductive tactics were sequential as sneakers developed into bourgeois males from one breeding season to the next (unpubl. data).

Throughout the breeding season (June and July) 2000, a group of nests was regularly monitored and focal observations on individually marked sneakers and females were conducted to identify whether sneakers associated with nests or followed females until they spawned. The study site consisted of a transect of 50 longitudinally aligned bricks. Every 2 weeks the bricks were inspected both during high and low tide and all animals were captured with a hand net, anaesthetized with MS-222, individually marked with coloured beads following the procedure described by Patzner \& Seiwald (1984), and several biometric and morphometric variables were recorded. Fish recovered in a container with abundant aeration and were released in the same place where they were captured. No mortality occurred during this procedure and, as the transect has been monthly monitored for another study still in progress, the beads from all recaptured animals were removed.

During low tide inspections the reproductive success of nest-holder males was calculated by estimating the number of eggs that the males were defending (Gonçalves et al., 2002). The sum of the areas covered with eggs calculated in all low tide inspections for a specific nest was taken as a measure of the total reproductive success of that nest for the breeding season. As eggs in this species take at most 15 days to hatch (Patzner \& Brandstätter, 1989) and low tide inspections were performed every 2 weeks, the danger of under- or overestimating reproductive success was low.

Focal observations were conducted while snorkelling from 1 June to 31 July on 22 sneakers and 22 females for a total of 30.0 and $21.7 \mathrm{~h}$, respectively. The same sneaker was observed from one to 14 times (mean \pm s.E. $=4 \cdot 09 \pm 0 \cdot 81$ ) and the same female from one to 11 times $(2 \cdot 95 \pm 0 \cdot 58)$, always on different days. After detecting a marked fish on the transect, a $5 \mathrm{~min}$ acclimation period was given to allow habituation to the observer followed by a $20 \mathrm{~min}$ focal observation period. The agonistic and courtship behaviour displayed by the focal fish or by other conspecifics with which the focal animal interacted were recorded on an underwater slate. Every $30 \mathrm{~s}$ the position of the fish was recorded in order to calculate the time spent by animals in bricks with and without nests and outside the transect. For each focal fish, the distance between the two most distant points in which the animal was observed during the observation was computed. As some fish were observed more than once, the average value of all observations recorded for each animal was used.

The transect was scanned on a daily basis by snorkelling, and the position (i.e. brick and hole) of all marked animals recorded. A total of 50 scans were 


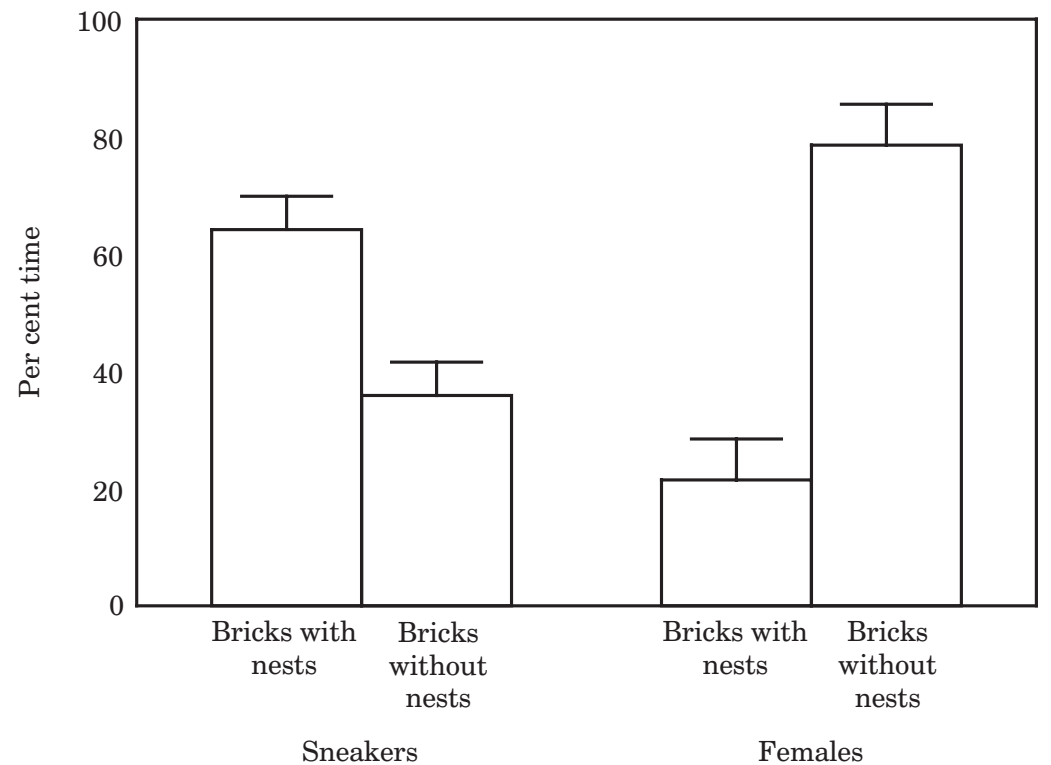

FIg. 1. Mean \pm S.E. relative time spent by sneakers $(n=22)$ and females $(n=22)$ on the transect, in bricks with and without nests during focal observations.

performed throughout the breeding season (June and July). For each fish the total number of times it occurred in the scans was calculated and an association index was computed for each brick (number of times the fish was present in that brick per total number of times the fish was seen in the transect).

As most of the data did not conform to the assumptions of parametric procedures, non-parametric two-tailed tests were applied throughout, using Statistica v.5.0 (Statsoft, 1995). Unless stated otherwise, group differences were compared with the Mann-Whitney test and correlations between variables with the Spearman's rank order correlation coefficient $\left(r_{\mathrm{s}}\right)$.

The distance between the two most distant points where a fish occurred within the $20 \mathrm{~min}$ observational period was higher for females (mean \pm S.E., females $=3 \cdot 26 \pm 0.33 \mathrm{~m}, \quad n=22 ; \quad$ sneakers $=1.85 \pm 0.34 \mathrm{~m}, \quad n=22 ; \quad P=0.002$ ) and females spent more time outside the transect (i.e. not associated with bricks) $($ mean \pm s.E., females $=51 \cdot 70 \pm 7 \cdot 04 \%, n=22$; sneakers $=10 \cdot 00 \pm 2 \cdot 06 \%, n=22$; $P<0.001)$. Considering only the time spent in the transect, sneakers spent more time in bricks with nests than without nests (Wilcoxon sign rank test, $n=22$; $P=0.036$; Fig. 1), while females spent the majority of time in bricks without nests (Wilcoxon sign rank test, $n=22, P=0 \cdot 003$; Fig. 1). While in the transect, sneakers visited fewer bricks than females [(number of bricks visited) (total time in transect $)^{-1}$, mean \pm S.E., females $=0 \cdot 15 \pm 0 \cdot 04, \quad n=22 ; \quad$ sneakers $=0 \cdot 04 \pm 0 \cdot 00$, $n=22 ; P<0 \cdot 001)]$.

The sneaking attempts per observation varied between zero and four (mean \pm S.E. $=$ $0 \cdot 69 \pm 0 \cdot 19$ ). Throughout the breeding season, the same sneaker was observed parasitizing nests located, at most, in two different bricks (mean \pm s.E. $=$ $1 \cdot 50 \pm 0 \cdot 14)$ and, except in one case, the two bricks were adjacent. 
The total number of times a fish was observed during scans was higher for sneakers than for females (females $=3 \cdot 50 \pm 0 \cdot 67, n=28$; sneakers $=7 \cdot 86 \pm 1 \cdot 33$, $n=21 ; P=0.003)$. The number of days between the first and the last observation during scans was higher for sneakers than for females (sneakers = $16 \cdot 45 \pm 3 \cdot 11$, range $=0-45$ days, $n=21 ;$ females $=9 \cdot 68 \pm 2 \cdot 98$, range $=0-48$ days, $n=28 ; P=0.002$ ), but nevertheless sneakers were found in a proportionally lower number of bricks (number of different bricks where a fish was found divided by the total number of times the fish occurred: females $=0.91 \pm 0 \cdot 03$, $n=28$; sneakers $=0.69 \pm 0 \cdot 06, n=21 ; P<0 \cdot 001)$.

The highest association indicies of sneakers and females that had a 'preferred brick' (i.e. a brick where they occurred more often than others) were compared. In 13 out of 17 sneakers the highest association index occurred in bricks that had at least one nest, while in six out of eight females the highest association index occurred in bricks without nests $\left(\chi^{2}\right.$, d.f. $\left.=1, P=0 \cdot 014\right)$.

Bricks with nests that received more eggs throughout the breeding season had a higher number of different sneakers associated with them (correlation between the total number of eggs calculated for each brick and the total number of sneakers observed in each brick: $\left.r_{\mathrm{s}}=0 \cdot 61, n=11, P=0 \cdot 046\right)$ and a tendency to also have more females $\left(r_{\mathrm{s}}=0 \cdot 58, n=11, P=0 \cdot 060\right)$. Sneakers in these bricks were larger in comparison with the ones found in less successful bricks $\left(r_{\mathrm{s}}=0.62, n=11, P=0.043\right)$, while no such correlation occurred for females $(n=9, P=0 \cdot 606)$.

The observational data presented here suggest that sneakers associated with particular nests and not with ripe females. Indeed, both sneakers and females were never observed shoaling and sneakers dispersed much less than females, both during the observations and scans. Females only approached nests to assess males or to spawn, while sneakers were almost permanently in visual contact with one or more nests, waiting for potential spawning events to occur, and were usually found associated with only one or two bricks throughout the 2 months of the observational period. It could thus be argued that parasitic males of $S$. pavo would be better described as satellites rather than sneakers, as they helped expel other sneakers from the vicinity of the nest (pers. obs.) and associated with specific nests (Taborsky, 1994, 1997, 2001). Satellites are often less attacked, however, by nesting males compared with other males (Oliveira et al., 2002), while during the present observations qualitative estimates suggest that the bourgeois males of $S$. pavo attacked 'resident' sneakers as often as 'intruder' sneakers. Furthermore, the elaborate female-mimicking behaviour displayed by sneakers suggests that they try to be mistaken for females and not to be recognized as co-operators.

The absence of satellites from this population may relate to the fact that nests are probably too costly to defend due to their scarcity and aggregation. The absence of territories hampers small males from co-operating with bourgeois males in the defence of an area around the nest and, thus, bourgeois males are not expected to benefit some small males over others.

Bricks with nests that received more eggs had more and larger sneakers associated with them. A similar pattern was found in Parablennius sanguinolentus parvicornis (Valenciennes), where males with satellites received more female visits and spawnings (Oliveira et al., 2002). Similarly to what was suggested 
for satellites of $P$. s. parvicornis, the present results may indicate that females prefer to mate with bourgeois males that have more or larger sneakers in the vicinity of their nest and that sneakers compete strongly for the access to highly successful nests, increasing their probability of fertilizing eggs. Future detailed experiments are necessary to clarify which mechanisms are leading to the higher reproductive success of nests with more and larger sneakers attached.

The sneakers' reproductive tactic is likely to be the result of the peculiar reproductive ecology of the population at Ria Formosa. The scarcity and aggregation of nests leads to an operational sex-ratio biased towards females and nesting males are the limiting reproductive resource. Thus, it should pay a sneaker to associate with a nest or group of nests rather than with females, as nests are the resources for which females compete.

The Ria Formosa Nature Park direction provided essential logistical support. During this study D.M.G. was funded by a PRAXIS XXI Ph.D. grant (BD/13436/97). The Portuguese Science and Technology Foundation provided financial support (UI\&D331/ 94). Two anonymous reviewers provided helpful comments on an earlier version of the manuscript.

\section{References}

Almada, V. C., Gonçalves, E. J., Santos, A. J. \& Baptista, C. (1994). Breeding ecology and nest aggregations in a population of Salaria pavo (Pisces: Blenniidae) in an area where nest sites are very scarce. Journal of Fish Biology 45, 819-830.

Almada, V. C., Gonçalves, E. J., Oliveira, R. F. \& Santos, A. J. (1995). Courting females: ecological constraints affect sex roles in a natural population of the blenniid fish, Salaria pavo. Animal Behaviour 49, 1125-1127.

Gonçalves, E. J., Almada, V. C., Oliveira, R. F. \& Santos, A. J. (1996). Female mimicry as a mating tactic in males of the blenniid fish Salaria pavo. Journal of the Marine Biological Association of the United Kingdom 76, 529-538.

Gonçalves, D., Simões, P. C., Chumbinho, A. C., Correia, M. J., Fagundes, T. \& Oliveira, R. F. (2002). Fluctuating asymmetries and reproductive success in the peacock blenny. Journal of Fish Biology 60, 810-820. doi: 10.1006/jfbi.2002.1877.

Oliveira, R. F., Almada, V. C., Forsgren, E. \& Gonçalves, E. J. (1999). Temporal variation in male traits, nesting aggregations and mating success in the peacock blenny. Journal of Fish Biology 54, 499-512. doi: 10.1006/jfbi.1998.0886.

Oliveira, R. F., Carvalho, N., Miranda, J., Gonçalves, E. J., Grober, M. \& Santos, R. S. (2002). The relationship between the presence of satellite males and nest-holder's mating success in the Azorean rock-pool blenny, Parablennius sanguinolentus parvicornis. Ethology 108, 223-235.

Patzner, R. A. \& Seiwald, M. (1984). Individual tagging of small fish. Aquaculture 40, 251-253.

Patzner, R. A. \& Brandstätter, R. (1989). Rearing of Blennius pavo Risso. Bulletin de L'Institut Oceánographique, Monaco 5, 223-226.

Statsoft (1995). STATISTICA for Windows. Tulsa, OK: Statsoft Inc.

Taborsky, M. (1994). Sneakers, satellites and helpers: parasitic and cooperative behaviour in fish reproduction. Advances in the Study of Behaviour 23, 1-100.

Taborsky, M. (1997). Bourgeois and parasitic tactics: do we need collective, functional terms for alternative reproductive behaviors? Behavioral Ecology and Sociobiology 41, 361-362.

Taborsky, M. (2001). The evolution of bourgeois, parasitic, and cooperative reproductive behaviors in fishes. The Journal of Heredity 92, 100-110. 